\title{
32. Isolation of Oryzanin Crystals (Antineuritic Vitamin) from Rice Polishings.
}

\author{
I. Report. \\ By Satoru ODAKE. \\ Agricultural Chemical Laboratory, Tokio Imperial University \\ (Faculty of Agriculture, Komaba, Tokyo).
}

(Comm. by U. SuzukI, M.I.A., March 12, 1981.)

In 1927, Jansen and Donath ${ }^{1}$ reported the isolation of antineuritic vitamin from rice polishings. The hydrochloride and the gold chloride double salt of the vitamin isolated by these authors in crystalline state, were stated to be represented by the formula. $\mathrm{C}_{6} \mathrm{H}_{10} \mathrm{~N}_{2} \mathrm{O}$. $\mathrm{HCl}$ m.p. $250^{\circ}$ and $\mathrm{C}_{6} \mathrm{H}_{10} \mathrm{~N}_{2} \mathrm{O} . \mathrm{HCl} . \mathrm{AuCl}_{3}$ respectively. The hydrochloride forms needle crystals, soluble in water and methyl alcohol but insoluble in cold absolute alcohol. It is precipitated by mercuric chloride, mercuric sulphate, potassium iod-iodide and Dragendorf's reagent. It gives also Diazoreaction. The protective dose of the hydrochloride for a bondol is stated to be $0.002 \mathrm{mg}$ and for a pigeon $0.03-0.06 \mathrm{mg}$ daily.

Soon after the appearance of this publication, the present author repeated the same experiment, following the method of the dutch authors. The preliminary result obtained is briefly given below :-

The material used in this experiment was the so called "Active Oryzanin ", supplied from Sankyo and Co. Tokio, where it is prepared in large scale according to the following process:-

1) $100 \mathrm{~kg}$ rice polishings are macerated with 800 liters of $0.3 \%$ sulphuric acid and after standing for three hours at room temperature, it is filtered through a cloth filter. The filtrate is then mixed with $7 \mathrm{~kg}$ finely powdered acid clay, well stirred and kept for a few hours. The acid clay adsorbes the greater part of the vitamin contained in the solution and subsides at the bottom. The supernatant solution is now syphoned off and the sediment is collected on a cloth filter, and after centrifuging it is treated with an excess of a $0.5 \%$ baryta solution, whereby the vitamin is liberated from the acid clay and goes in the solution. After a short time, it is filtered and the filtrate is freed from baryta by sulphuric acid and evaporated in vacuum to a small volume. Hereupon it is added with some absolute alcohol, to remove proteins and other impurities, and the alcoholic filtrate is evaporated to a brown syrup. It is tolerably active, the curative dose for a pigeon being ca. $10 \mathrm{mg}$ per day.

For further purification, this syrup is dissolved in a little water, acidified with sulphuric acid, until it reaches $5 \%$ of the solution and

1) Mededeelingen van den Dienst der Volksgesondheid in Ned.-Indië. (1927). 
precipitated with phosphotungstic acid. The precipitate thus obtained is now suspended in water and decomposed with baryta in usual way and the filtrate containing the vitamin is freed from baryta by sulphuric acid and evaporated in vacuum. In this way the so-called "Active Oryzanin" is obtained as a light brown amorphous mass. The curative dose of this preparation is ca. $4 \mathrm{mg}$ per day for a pigeon. The yield is $0.03-0.04 \%$ of the original polishings, i.e. nearly half of the vitamin contained in the polishings is recovered in this fraction.

2) Starting now from the "Active Oryzanin," the author tried to isolate the vitamin in crystalline state, according to the method of Jansen and Donath, slightly modified as follows:-

$100 \mathrm{~g}$ "Active Oryzanin" were dissolved in three liters water, and acidified with dilute sulphuric acid until the reaction becomes $\mathrm{pH}=2.6$. $100 \mathrm{~g}$ silver nitrate were now added in substance, well stirred until it was completely dissolved. A thick voluminous precipitate thus formed was collected on a suction filter and washed with a little acidulated water of $\mathrm{pH}=2.6$. This precipitate was designated as Fraction $\mathrm{I}$. The filtrate from Fraction I was fractionally precipitated by gradually adding baryta water, and the precipitates formed at $\mathrm{pH}=4.5,6.8$ and 9.0 were separately collected, and designated as Fraction II, III and IV, respectively. The filtrate from Fraction IV, was treated with a little excess of hydrochloric and sulphuric acid, to remove the silver and baryta and the filtrate therefrom was again precipitated with phosphotungstic acid ...... Fraction V.

From these fractions, the following substances were isolated:-

From Fraction I: Adenin and Hypoxanthin

, II : Nicotinic acid and Adenin

" IV : Nicotinic acid and a base, $\left(\mathrm{C}_{3} \mathrm{H}_{6} \mathrm{~N}_{2}\right)_{x}$

„ V : Nicotinic acid, Cholin and a base $\left(\mathrm{C}_{8} \mathrm{H}_{10} \mathrm{NO}_{3} \cdot \mathrm{HCl}\right.$ ?)

Fraction III was proved to contain a greater part of the vitamin, so it was suspended in water, treated with a little excess of hydrochloric and sulphuric acid to remove the silver and baryta and precipitated with phosphotungstic acid. The precipitate thus formed was decomposed with baryta water in usual way and the filtrate, after removing the baryta by sulphuric acid, was evaporated in vacuum. A hell brown syrup thus obtained, was dissolved in a little absolute alcohol, a little insoluble residue was filtered off and an alcoholic solution of platinic chloride was added. The precipitate formed thereby was collected after 24 hours, suspended in water, and after adding a little hydrochloric acid, it was decomposed with hydrogen sulphide. The filtrate of platinic sulphide was evaporated to dryness. A hell brown syrup thus obtained was dissolved in a little absolute alcohol and aceton was cautiously 
added to it. The resinous substance separating at first was filtered off and the clear filtrate was further treated with aceton until a white turbidity is produced. On keeping it in an ice box for a long time, colourless sphaeric crystals, partly contaminated with oily substance separated out at the bottom and the wall of the vessel. The supernatant solution was now decanted into another vessel and treated with more aceton, whereby a second crystallization was obtained.

The crude crystals adhering to the vessel could easily be collected by rubbing with a little absolute alcohol, the oily matter being easily soluble in the latter solvent.

In this way, from $2 \mathrm{~kg}$ "Active Oryzanin" about $1.3 \mathrm{~g}$ crystalline product were obtained.

This product was now repeatedly recrystallized from alcohol and aceton and several fractions were separated and tested for antineuritic potency by animal experiment. In this way it was confirmed that the crystals melting at $253^{\circ}$ (not corrected) were only slightly active, while those melting at $220^{\circ}$ (not corrected) was more active, nevertheless it was revealed under the polarization microscope that the crystals were still contaminated with some amorphous substance. Only the crystals melting at $250^{\circ}$ (not corrected) were quite uniform and possessed the highest activity. So this fraction was subjected to analysis :

Analysis :-

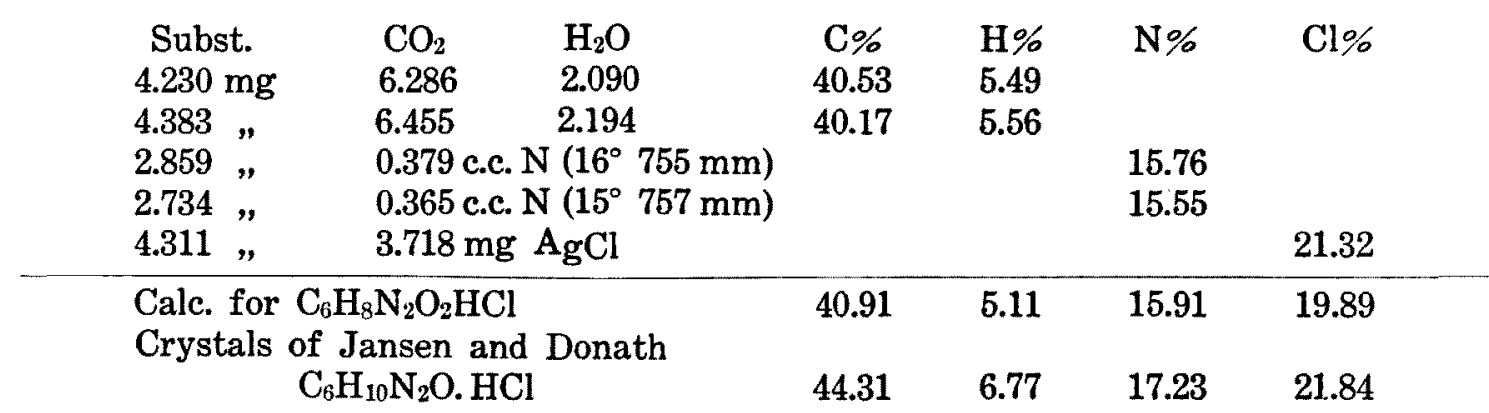

Unfortunately the result does not agree with that of Jansen and Donath. Whether the crystals still contained some impurities must be investigated later on.

The sample used for analysis, is easily soluble in water, difficultly in absolute alcohol and insoluble in aceton benzol and ether. It is precipitated by phosphotungstic acid, and gives a white turbidity with mercuric sulphate. It gives also strong Diazo-reaction. These properties agree well with the report of Jansen and Donath, the difference being that the author's crystals were monoclinic plates, and not needles and the melting point was somewhat higher than that of the dutch authors.

The antineuritic potency of the analysed sample was tested on pigeons and white rats with the following results:- 
1) When a pigeon, suffering from polyneuritis by exclusive feeding with polished rice, was injected daily with $0.01 \mathrm{mg}$ of these crystals, it recovered in a few days. By giving $0.02 \mathrm{mg}$, the recovery was more rapid, and the symptoms of the disease disappeared in few hours. With $0.05 \mathrm{mg}$ gradual increase in body weight was observed.

3) When a pigeon was previously fed on a B-free diet, consisting of $70 \%$ purified starch, $15 \%$ meat protein $10 \%$ butter and $5 \%$ McCollum's salt mixture, the recovery was better and the increase of body weight after injection was more marked.

3) When a pigeon fed on the B-free diet mentioned above, was administered from the beginning with $0.02 \mathrm{mg}$ per os daily, it remained in perfect health for 50 days, though the body weight declined gradually. By removing the crystals, the animal showed the signs of polyneuritis after 10 days.

4) Young albino rat, fed on the B-free diet, developed the disease after 14 days. By giving now, $0.02 \mathrm{mg}$ per os, it quickly recovered and resumed the growth with nearly normal rate.

5) Young rat, fed on the same diet as above, supplemented with $0.02 \mathrm{mg}$ daily from the beginning of the experiment remained for 70 days in perfect health and continued to grow with the rate of 1-1.2 $\mathrm{g}$ daily.

Whether the crystals tested represent the so called Vitamin $\mathrm{B}^{1}$ or whether they are the mixture of $\mathrm{B}^{1}$ and $\mathrm{B}^{2}$ must be investigated later on.

The author expresses his sincere thanks to Prof. U. Suzuki for his kind advise and encouragement throughout the work. Thanks are due to Mr. Iwasa of Sankyo and Co. for kind supply of the valuable material. The author is also indebted to Messrs. M. Kamada and T. Yamagishi for their kind assistance, both in chemical and biological experiment.

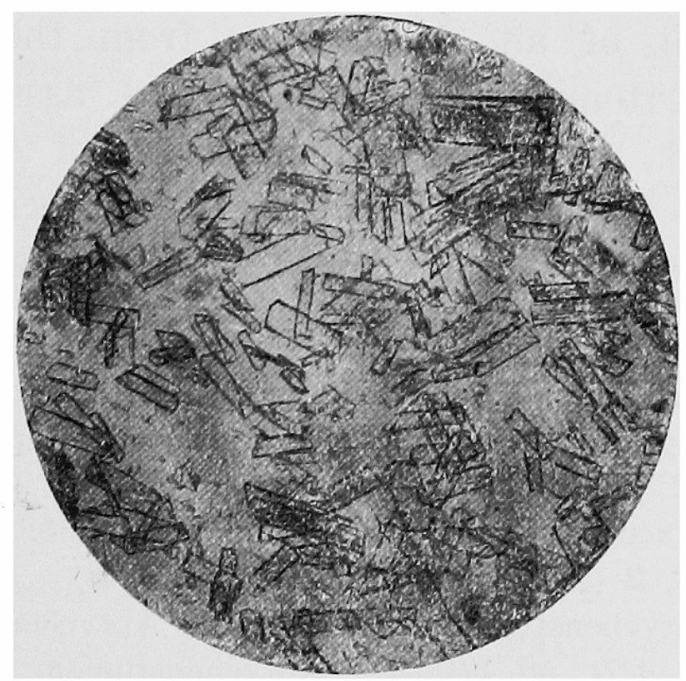

Oryzanin-Hydrochloride.

Leitz. III $\times \mathbf{Z}$. 